\title{
Long-term Outcomes and Risk Factors for Reoperation After Surgical Treatment for Gastrointestinal Crohn Disease According to Anti-tumor Necrosis Factor- $\alpha$ Antibody Use: 35 Years of Experience at a Single Institute in Korea
}

\author{
Sang Mok Lee, Eon Chul Han, Seung-Bum Ryoo, Heung-Kwon Oh ${ }^{1}$ Eun Kyung Choe 2 , Sang Hui Moon, \\ Joo Sung Kim³, Hyun Chae Jung 3 , Kyu Joo Park \\ Department of Surgery, Seoul National University College of Medicine, Seoul; ${ }^{1}$ Department of Surgery, Seoul National University Bundang \\ Hospital, Seoul National University College of Medicine, Seongnam; ${ }^{2}$ Healthcare Research Institute, Seoul National University Hospital \\ Healthcare System Gangnam Center, Seoul; ${ }^{3}$ Department of Internal Medicine, Seoul National University College of Medicine, Seoul, Korea
}

Purpose: Crohn disease is characterized by high rates of recurrence and reoperations. However, few studies have investigated long-term surgical outcomes in Asian populations. We investigated risk factors for reoperation, particularly those associated with anti-tumor necrosis factor- $\alpha$ (anti-TNF- $\alpha$ ) antibody use, and long-term follow-up results.

Methods: We reviewed the records of 148 patients (100 males and 48 females) who underwent surgery for gastrointestinal Crohn disease and retrospectively analyzed long-term outcomes and risk factors.

Results: The mean age at diagnosis was 28.8 years. Thirty-eight patients $(25.7 \%)$ received monoclonal antibody treatment before reoperation. A small bowel and colon resection was most commonly performed (83 patients, 56.1\%). The median follow-up was 149 months, during which 47 patients underwent reoperation. The median interval between the primary and the secondary surgeries was 65 months, with accumulated reoperation rates of $16.5 \%, 31.8 \%$, and $57.2 \%$ after 5,10 , and 15 years, respectively. Obstruction was the most common indication for reoperation (37 patients, 25.0\%). In a multivariable analysis, age $<17$ years at diagnosis $(\mathrm{A} 1)$ (odds ratio $[\mathrm{OR}], 2.20 ; \mathrm{P}=0.023)$, penetrating behavior (B3) (OR, 4.39; $\mathrm{P}<0.001)$, and no azathioprine use $(\mathrm{OR}, 2.87 ; \mathrm{P}=0.003)$ were associated with reoperation. Anti-TNF- $\alpha$ antibody use did not affect the reoperation rate $(\mathrm{P}=0.767)$.

Conclusion: We showed a high reoperation rate regardless of treatment with anti-TNF- $\alpha$ antibody, which indicates that recurrent surgery is still needed to cure patients with gastrointestinal Crohn diseases. Younger age at primary operation, penetrating behavior, and no azathioprine use were significant factors associated with reoperation for gastrointestinal Crohn disease.

Keywords: Crohn disease; Reoperation; Azathioprine; Infliximab

Received: July 18,2015 - Accepted: August 5, 2015

Correspondence to: Kyu Joo Park, M.D.

Department of Surgery, Seoul National University College of Medicine,

103 Daehak-ro, Jongno-gu, Seoul 03080, Korea

Tel: +82-2-2072-2901, Fax: +82-2-766-3975

E-mail: kjparkmd@plaza.snu.ac.kr

(C) 2015 The Korean Society of Coloproctology

This is an open-access article distributed under the terms of the Creative Commons Attribution NonCommercial License (http://creativecommons.org/licenses/by-nc/3.0) which permits unrestricted non-

commercial use, distribution, and reproduction in any medium, provided the original work is properly cited.

\section{INTRODUCTION}

Gastrointestinal Crohn disease (CD) is a chronic inflammatory bowel disease with an unpredictable clinical course. Although long-term management of $\mathrm{CD}$ can be achieved with anti-inflammatory or immunosuppressive drugs, most CD patients experience repeated relapses and remission of inflammation. Surgical treatment becomes necessary when an intestinal obstruction or perforation occurs, with or without an abscess or fistula. Currently, there is no cure for $\mathrm{CD}$; approximately $80 \%$ of patients un- 
dergo surgery during their lifetimes, and more than half of these patients require reoperation for recurrent $\mathrm{CD}$ after surgical treatment [1-5]. Recent reports indicate that infliximab, a tumor necrosis factor- $\alpha$ (TNF- $\alpha$-specific antibody, is significantly prophylactic against recurrent $\mathrm{CD}$ [6]. A human monoclonal antibody, adalimumab, has also been introduced with encouraging results $[7,8]$. However, a complete cure for $\mathrm{CD}$ is not yet available, despite these new treatment modalities.

Many studies in Western countries have investigated the risk factors for reoperation in patients with $\mathrm{CD}$ and have identified the extent of disease at diagnosis, the presence of a perianal fistula, family history, smoking history, and perforating disease as risk factors. Accordingly, these risk factors are important for the postsurgical management of patients with $\mathrm{CD}$ [5, 9-12]. However, the risk factors for reoperation in Asian patients may differ from those in Western patients because Asian populations exhibit clinical characteristics (e.g., serologic and genetic types) different from those of Western populations $[13,14]$. Although we previously reported the surgical outcomes and high rate of reoperation for our patients with $\mathrm{CD}$, which were similar to those of Western patients, no studies have investigated the long-term surgical outcomes related to reoperation according to anti-TNF- $\alpha$ antibody use in Korean patients with $\mathrm{CD}$. This study, therefore, aimed to evaluate the long-term outcomes of surgical treatment for gastrointestinal CD according to anti-TNF- $\alpha$ antibody use and to analyze the risk factors for reoperation in Korean patients with CD.

\section{METHODS}

This study was approved by the Institutional Review Board of the Seoul National University Hospital (H-1503-088-657). We identified 148 patients who had undergone surgery for gastrointestinal CD at our institute from 1978 to 2013. Most patients were diagnosed according to preoperative clinical impressions, endoscopic findings, and pathologic results. Patients who had previously undergone surgery for anal $\mathrm{CD}$ alone were excluded from this study. We retrospectively reviewed the patient's medical records to investigate sex, ages at diagnosis and primary operation, smoking habits, body mass index (BMI), medication history, indications of primary operation and reoperation, types of primary operation and reoperation, location of disease, length of bowel resection, and postoperative complications.

We used the Montreal classification to classify patients with CD; this is a 2005 revision of the Vienna classification (Table 1) [15]. We also compared patients with BMIs above and below a BMI threshold of $18.5 \mathrm{~kg} / \mathrm{m}^{2}$ to determine the effects of being underweight (BMI $<18.5 \mathrm{~kg} / \mathrm{m}^{2}$ ) and nonunderweight (BMI $\geq 18.5 \mathrm{~kg} /$ $\mathrm{m}^{2}$ ) [16]. We defined a primary operation as the first operation for a patient with gastrointestinal CD; a subsequent operation because of disease recurrence and relapse was defined as a reoperation. The long-term cumulative reoperation rates before and after 2002 , the first year of anti TNF- $\alpha$ antibody (infliximab) use, were
Table 1. The Montreal classification of Crohn disease

\begin{tabular}{lc}
\hline Class & Criteria \\
\hline Age at diagnosis & \\
A1 & $<17 \mathrm{yr}$ \\
A2 & $17-40 \mathrm{yr}$ \\
A3 & $>40 \mathrm{yr}$ \\
Location & Ileal \\
L1 & Colonic \\
L1 & Ileocolonic \\
L3 & Isolated upper disease \\
L4 modifier & \\
Behavior & Nonstricturing, nonpenetrating \\
B1 & Stricturing \\
B2 & Penetrating \\
B3 & Perineal disease modifier \\
\hline Bp modifier &
\end{tabular}

evaluated and compared. We further verified the risk factors for reoperation, including the use of anti-TNF- $\alpha$ antibody, in our study population.

The statistical analysis was performed using IBM SPSS Statistics ver. 21.0 (IBM Co., Armonk, NY, USA). In a univariate analysis of the risk factors for reoperation, the chi-square test was used to compare categorical variables, and the Student $\mathrm{t}$-test was used to compare continuous variables. The cumulative reoperation rate was derived from a Kaplan-Meyer analysis. In the multivariate analysis, a Cox regression analysis was used to compare the cumulative reoperation rates. Statistical significance was indicated at a P-value $<0.05$.

\section{RESULTS}

\section{Clinical characteristics and primary operation}

The patients' clinical characteristics are shown in Table 2. One hundred patients were male, and 48 were female. The mean ages at diagnosis and primary operation were 28.8 and 31.9 years, respectively, and the mean interval from diagnosis to primary operation was 57.7 months (range, 0-209 months). Eighty (54.1\%) and 60 patients $(40.5 \%)$ had taken medication for $\mathrm{CD}$ before and after the primary operation, respectively. Thirty-eight patients (25.7\%) used anti-TNF- $\alpha$ antibodies. An additional 16 patients used infliximab before the primary operation, and 22 began to use infliximab after the primary operation. Three patients used adalimumab and two patients used both infliximab and adalimumab after primary operation.

The rate of primary surgery for $\mathrm{CD}$ has recently increased at our institute (Fig. 1). Obstruction ( $\mathrm{n}=37,25.0 \%)$ was the most common indication for primary surgery, and small bowel and colon 
Table 2. Clinical characteristics of patients with Crohn disease

\begin{tabular}{|c|c|}
\hline Characteristic & Value \\
\hline \multicolumn{2}{|l|}{ Sex } \\
\hline Male & $100(67.6)$ \\
\hline Female & $48(32.4)$ \\
\hline Age at diagnosis (yr) & $28.8 \pm 14.4$ \\
\hline Age at primary operation (yr) & $31.9 \pm 13.6$ \\
\hline Period from diagnosis to primary operation (mo) ${ }^{\mathrm{a}}$ & $57.7 \pm 61.1$ \\
\hline \multicolumn{2}{|l|}{ Body mass index (kg/m²) } \\
\hline$\geq 18.5$ & $69(54.8)$ \\
\hline$<18.5$ & $57(45.2)$ \\
\hline \multicolumn{2}{|l|}{ Smoking } \\
\hline Yes & $23(16.3)$ \\
\hline No & $118(83.7)$ \\
\hline \multicolumn{2}{|l|}{ Montreal classification } \\
\hline \multicolumn{2}{|l|}{ Age at diagnosis } \\
\hline A1 & $27(18.2)$ \\
\hline A2 & $92(62.2)$ \\
\hline A3 & $29(19.6)$ \\
\hline \multicolumn{2}{|l|}{ Location } \\
\hline L1 & $80(55.6)$ \\
\hline L2 & $19(13.2)$ \\
\hline L3 & $45(31.3)$ \\
\hline L4 & $30(20.3)$ \\
\hline \multicolumn{2}{|l|}{ Behavior } \\
\hline B1 & $14(9.5)$ \\
\hline B2 & $56(38.1)$ \\
\hline B3 & $77(52.4)$ \\
\hline Bp & $36(24.7)$ \\
\hline \multicolumn{2}{|l|}{ Preoperative medication for CD } \\
\hline Yes & $80(54.1)$ \\
\hline No & $60(40.5)$ \\
\hline \multicolumn{2}{|l|}{ Medication } \\
\hline 5-ASA & $119(80.4)$ \\
\hline Azathioprine & $111(75.0)$ \\
\hline Steroid & $110(74.3)$ \\
\hline Infliximab/adalimumab & $38(25.7)$ \\
\hline \multicolumn{2}{|l|}{ TB medication before diagnosis } \\
\hline Yes & $53(35.8)$ \\
\hline No & $94(63.5)$ \\
\hline \multicolumn{2}{|l|}{ Indication of primary operation } \\
\hline Obstruction & $37(25.0)$ \\
\hline Abdominal abscess or mass & $24(16.2)$ \\
\hline
\end{tabular}

(Continued to the next)
(Continued)

\begin{tabular}{|c|c|}
\hline Characteristic & Value \\
\hline Diagnostic laparotomy & $22(14.9)$ \\
\hline Medical intractability & $21(14.2)$ \\
\hline Perforation & $19(12.8)$ \\
\hline Enterocutaneous fistula & $18(12.2)$ \\
\hline Internal fistula & $7(4.7)$ \\
\hline \multicolumn{2}{|l|}{ Type of primary operation } \\
\hline Small bowel and colon resection & $83(56.1)$ \\
\hline Small bowel resection & $53(35.8)$ \\
\hline Colon resection & $10(6.8)$ \\
\hline Stricturoplasty only & $1(0.7)$ \\
\hline Drainage of abdominal abscess & $1(0.7)$ \\
\hline \multicolumn{2}{|l|}{ Stricturoplasty } \\
\hline Yes & $22(14.9)$ \\
\hline No & $127(85.1)$ \\
\hline \multicolumn{2}{|l|}{ Stoma formation } \\
\hline Yes & $5(3.4)$ \\
\hline No & $143(96.6)$ \\
\hline \multicolumn{2}{|l|}{ Bypass } \\
\hline Yes & $2(1.4)$ \\
\hline No & $146(98.6)$ \\
\hline Resected bowel length (cm) & $47.8 \pm 37.2$ \\
\hline$>40$ (median) & $69(49.3)$ \\
\hline$\leq 40$ (median) & $71(50.7)$ \\
\hline \multicolumn{2}{|l|}{ Postoperative complications } \\
\hline Yes & $39(29.8)$ \\
\hline No & $92(70.2)$ \\
\hline
\end{tabular}

Values are presented as number (\%) or mean \pm standard deviation. CD, Crohn disease; ASA, Aminosalicylic acid; TB, tubercle bacillus. aPatients who were diagnosed after surgery had been excluded.

resection $(\mathrm{n}=83,56.1 \%)$ was the most common surgical procedure. Twenty-two patients (14.9\%) underwent a stricturoplasty, and 5 patients (3.4\%) underwent stoma formation. Bowel resection was performed in 147 patients, with a median bowel resection length of $40 \mathrm{~cm}$ (range, 8-325 cm). Thirty-nine patients (29.8\%) experienced postoperative complications (Table 3). The most common complication was wound seroma $(\mathrm{n}=16,41.0 \%)$.

\section{Follow-up and reoperation for recurrence}

The median follow-up period was 149 months (range, 5-395 months), and 47 patients (31.8\%) underwent reoperation after a median interval of 198 months (range, 14-330 months). Bowel obstruction ( $\mathrm{n}=14,29.8 \%)$ was the most common indication for reoperation, and small bowel resection $(\mathrm{n}=27,27.4 \%)$ was the most common reoperation procedure (Table 4). Six patients (4.1\%) 


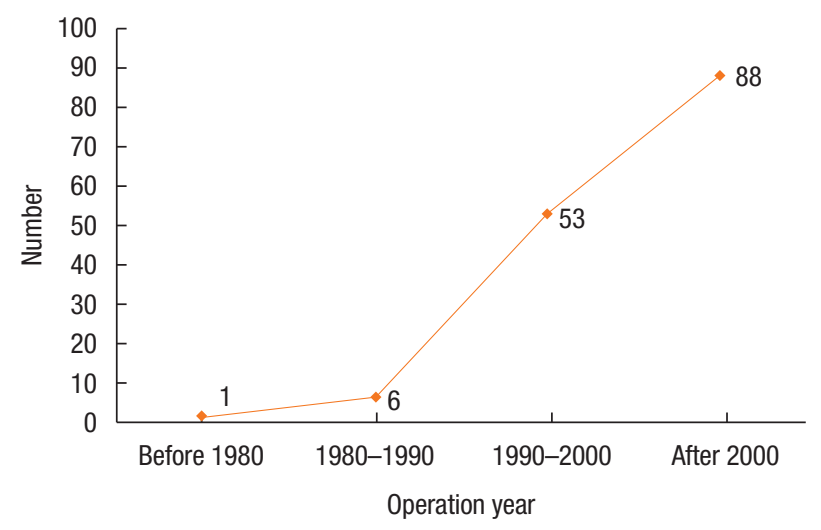

Fig. 1. Changes in the numbers of surgeries for intestinal Crohn disease (every 10 years).

Table 3. Postoperative complications after primary operation $(n=39)$

\begin{tabular}{lc}
\hline Complication & No. of patients (\%) \\
\hline Wound seroma & $16(41.0)$ \\
Enterocutaneous fistula & $6(15.4)$ \\
Ileus & $5(12.8)$ \\
Intra-abdominal abscess & $5(12.8)$ \\
Anastomosis site leakage & $3(7.7)$ \\
Urinary tract infection & $2(5.1)$ \\
Fever of unknown origin & $1(2.6)$ \\
Cerebrovascular accident & $1(2.6)$ \\
Total & 39 \\
\hline
\end{tabular}

required a third operation, $4(2.7 \%)$ a fourth operation, and 1 patient $(0.7 \%)$ a fifth operation (Fig. 2), and they all had undergone a small bowel and colon resection (Table 5). After the primary operation, the 5-, 10-, 15-, and 20-year cumulative reoperation rates were $17.4 \%, 31.5 \%, 57.0 \%$, and $68.7 \%$, respectively (Fig. 3 ).

In the reoperation group, 29 patients underwent a primary operation for penetrating disease, among whom 22 (75.9\%) required reoperation for recurrent penetrating disease. Seventeen patients underwent a primary operation for nonpenetrating disease, among whom 10 (58.8\%) required reoperation for recurrent nonpenetrating disease. A significant difference in sustained disease behavior was observed between the groups $(\mathrm{P}=0.029)$.

\section{Analysis of risk factors for reoperation}

In a univariate analysis of the risk factors for reoperation, according to the Montreal classification, the behavior (B) significantly affected the reoperation rate $(\mathrm{P}=0.010)$, as did the interval from diagnosis to primary operation $(\mathrm{P}=0.027)$. However, medication use, including anti-TNF- $\alpha$ antibodies (infliximab or adalimumab), did not significantly affect the reoperation rate (Table 6). In a multivariate analysis via a logistic regression, an age $<17$ years at diagnosis (A1) (odds ratio [OR], 2.20; 95\% confidence interval

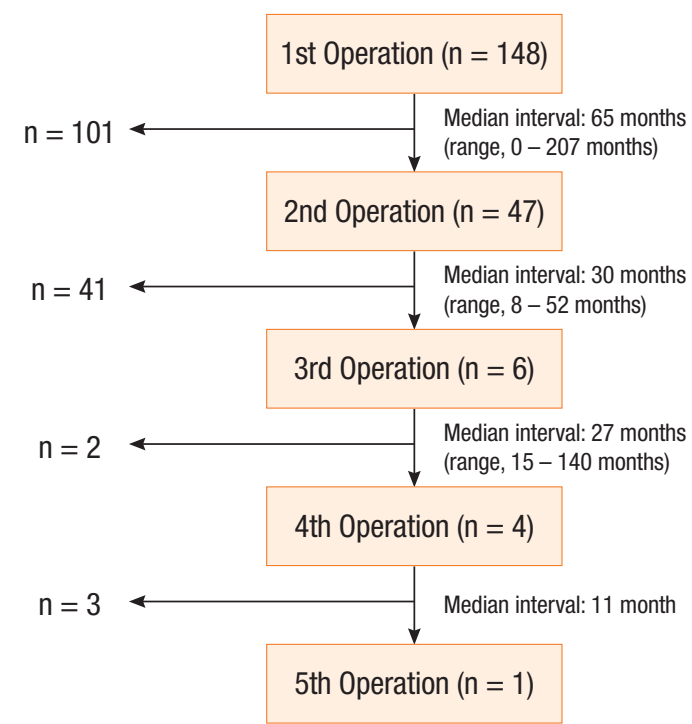

Fig. 2. Reoperation during the follow-up period.

Table 4. Reoperation for gastrointestinal Crohn disease

\begin{tabular}{lc}
\hline Reoperation & No. of patients (\%) \\
\hline Indication of reoperation & $15(31.9)$ \\
Obstruction & $11(23.4)$ \\
Enterocutaneous fistula & $8(17.0)$ \\
Perforation & $5(10.6)$ \\
Internal fistula & $5(10.6)$ \\
Abdominal abscess or mass & $2(4.3)$ \\
Medical intractability & $1(2.1)$ \\
Diagnostic laparotomy & \\
Type of reoperation & $27(57.4)$ \\
Small bowel resection & $15(31.9)$ \\
Small bowel and colon resection & $4(8.5)$ \\
Colon resection & $1(2.1)$ \\
Proximal gastrectomy & \\
Stoma formation & $4(8.5)$ \\
Yes & $43(91.5)$ \\
No & \\
Stricturoplasty & $5(10.6)$ \\
Yes & $42(89.4)$ \\
\hline No & \\
\hline
\end{tabular}

[CI], 1.12-4.31; $\mathrm{P}=0.023)$, penetrating behavior (B3) (OR, 4.39; 95\% CI, 2.19-8.80; $\mathrm{P}<0.001)$, and no azathioprine use $(\mathrm{OR}, 2.87$; $95 \% \mathrm{CI}, 1.43-5.76 ; \mathrm{P}=0.003)$ were associated with a significantly higher reoperation rate (Table 7$)$. In contrast, no significant difference in the cumulative reoperation rate was observed according to the year of primary operation (before and after 2002) rela- 
Table 5. Operations performed after reoperation for gastrointestinal Crohn disease

\begin{tabular}{lc}
\hline Reoperation & No. of patients (\%) \\
\hline Indication of reoperation & \\
Enterocutaneous fistula & $4(36.4)$ \\
Obstruction & $4(36.4)$ \\
Perforation & $2(18.2)$ \\
Abdominal abscess or mass & $1(9.1)$ \\
Type of reoperation & \\
Small bowel and colon resection & $11(100)$ \\
Stoma formation & \\
Yes & $0(0)$ \\
No & $11(100)$ \\
Stricturoplasty & \\
Yes & $1(9.1)$ \\
No & $10(90.9)$ \\
\hline
\end{tabular}

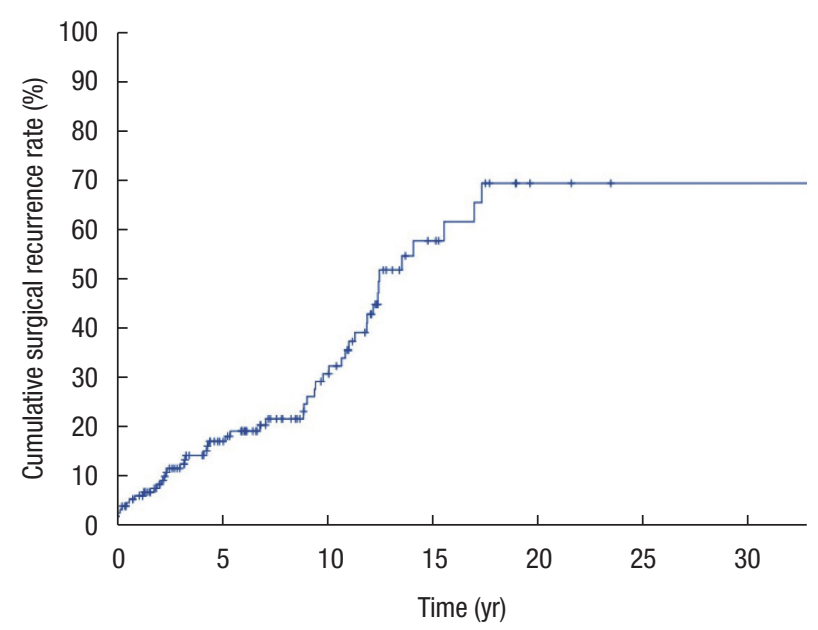

Fig. 3. Cumulative reoperation rate for intestinal Crohn disease.

tive to anti-TNF- $\alpha$ antibody availability $(\mathrm{P}=0.984$ and $\mathrm{P}=0.767$, respectively) (Fig. 4).

\section{DISCUSSION}

In this study of a Korean population, the cumulative reoperation rates for gastrointestinal CD were found to be $31.8 \%$ and $68.9 \%$ at 10 and 20 years after the primary operation, respectively. An age $<17$ years at diagnosis (A1), penetrating disease (B3), and no azathioprine use were found to be significant risk factors for reoperation in patients with CD. However, anti-TNF- $\alpha$ antibody use was not a significant risk factor. In eastern Asian countries (e.g., Korea, China, and Japan), the incidence of CD has recently increased, despite the traditional categorization of these areas as
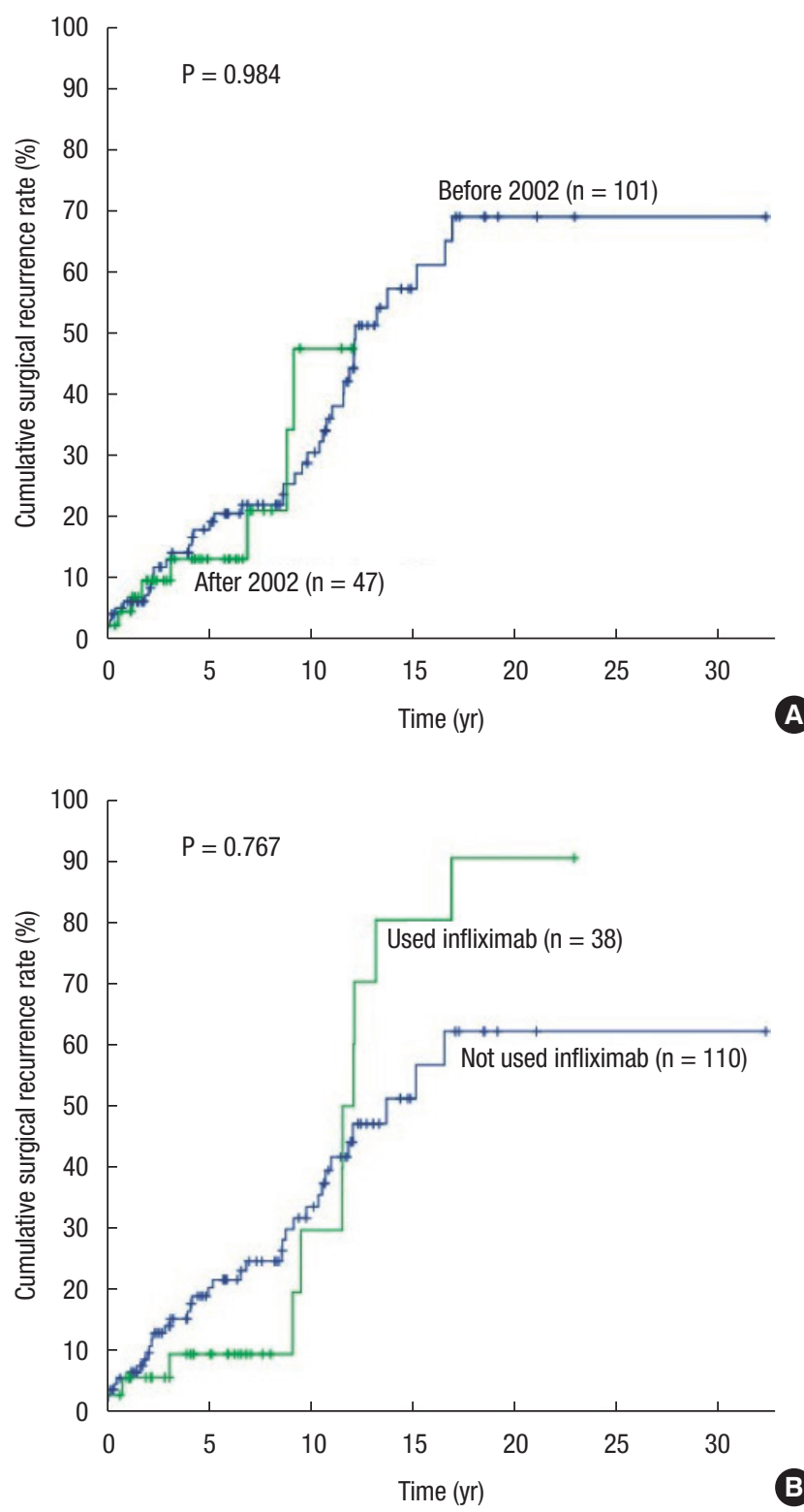

Fig. 4. Comparisons of infliximab use (A) between groups treated and not treated with infliximab and (B) between groups diagnosed before and after 2002 (the year infliximab became available as a treatment option).

countries with low $\mathrm{CD}$ incidence. In Korea, the reported annual incidence rate has increased from 1.34 per 100,000 inhabitants in 1986 to 11.24 per 100,000 inhabitants in 2005 [17, 18]. Our data similarly showed an increase in the number of patients with $\mathrm{CD}$ who had undergone surgery (Fig. 1), and our observed reoperation rates were as high as those in Western studies of CD $(38 \%$ and $52 \%$ at 10 and 20 years, respectively) $[9,19]$. Similar reports of the long-term outcomes ( $<35$ years) of patients with $\mathrm{CD}$ in Asian countries are very rare. Given the dramatic changes in $\mathrm{CD}$ 
Table 6. Comparison of the reoperation and the no reoperation groups

\begin{tabular}{|c|c|c|c|}
\hline Variable & $\begin{array}{l}\text { Reoperation (+) } \\
\quad(n=47)\end{array}$ & $\begin{array}{l}\text { Reoperation }(-) \\
\quad(n=101)\end{array}$ & P-value \\
\hline Sex & & & 0.260 \\
\hline Male & $35(35.0)$ & $65(65.0)$ & \\
\hline Female & $12(25.0)$ & $36(75.0)$ & \\
\hline Age at diagnosis (yr) & & & 0.601 \\
\hline$>27^{a}$ & $21(29.6)$ & $50(70.4)$ & \\
\hline$\leq 27$ & $26(33.8)$ & $51(66.2)$ & \\
\hline Age at primary operation (yr) & & & 0.078 \\
\hline$>31^{a}$ & $17(24.3)$ & $53(75.7)$ & \\
\hline$\leq 31$ & $30(38.5)$ & $48(61.5)$ & \\
\hline $\begin{array}{l}\text { Period from diagnosis to } \\
\text { primary operation (mo) }\end{array}$ & & & $0.027^{*}$ \\
\hline$>34^{\mathrm{a}}$ & $9(20.5)$ & 35 (79.5) & \\
\hline$\leq 34$ & $21(42.9)$ & $28(57.1)$ & \\
\hline Body mass index $\left(\mathrm{kg} / \mathrm{m}^{2}\right)$ & & & 0.676 \\
\hline$\geq 18.5$ & $17(24.6)$ & $52(75.4)$ & \\
\hline$<18.5$ & $12(21.1)$ & $45(78.9)$ & \\
\hline Smoking & & & 0.143 \\
\hline Yes & $4(17.4)$ & $19(82.6)$ & \\
\hline No & $42(35.6)$ & $76(64.4)$ & \\
\hline \multicolumn{4}{|l|}{ Montreal classification } \\
\hline Age at diagnosis & & & 0.124 \\
\hline$A 1$ & $13(48.1)$ & $14(51.9)$ & \\
\hline $\mathrm{A} 2$ & 27 (29.3) & $65(70.7)$ & \\
\hline A3 & $7(24.1)$ & $22(75.9)$ & \\
\hline Location & & & 0.068 \\
\hline L1 & $28(35.0)$ & $52(65.0)$ & \\
\hline L2 & $9(47.4)$ & $10(52.6)$ & \\
\hline L3 & $9(20.0)$ & $36(80.0)$ & \\
\hline$\left\llcorner 4^{b}\right.$ & $8(26.7)$ & $22(73.3)$ & 0.661 \\
\hline Behavior & & & $0.010^{*}$ \\
\hline B1 & $0(0)$ & $14(100)$ & \\
\hline B2 & $17(30.4)$ & $39(69.6)$ & \\
\hline B3 & $29(37.7)$ & $48(62.3)$ & \\
\hline $\mathrm{Bp}^{\mathrm{b}}$ & $16(44.4)$ & $20(55.6)$ & 0.064 \\
\hline Preoperative medication for $\mathrm{CD}$ & & & 0.285 \\
\hline Yes & $22(27.5)$ & $58(72.5)$ & \\
\hline No & $24(36.4)$ & $42(63.6)$ & \\
\hline Medication & & & \\
\hline
\end{tabular}

\begin{tabular}{|c|c|c|c|}
\hline Variable & $\begin{array}{l}\text { Reoperation }(+) \\
\quad(\mathrm{n}=47)\end{array}$ & $\begin{array}{l}\text { Reoperation }(-) \\
\quad(n=101)\end{array}$ & P-value \\
\hline 5-ASA & $36(30.5)$ & $82(69.5)$ & 0.518 \\
\hline Azathioprine & $31(27.9)$ & $80(72.1)$ & 0.103 \\
\hline Steroid & $34(30.9)$ & $76(69.1)$ & 0.692 \\
\hline Infliximab/adalimumab & $11(28.9)$ & $27(71.1)$ & 0.840 \\
\hline TB medication before diagnosis & & & 0.361 \\
\hline Yes & $14(30.4)$ & $39(38.6)$ & \\
\hline No & $32(69.6)$ & $62(61.4)$ & \\
\hline Indication of primary operation & & & $0.017^{*}$ \\
\hline Obstruction & $10(27.0)$ & $27(73.0)$ & \\
\hline Abdominal abscess or mass & $2(8.3)$ & $22(61.9)$ & \\
\hline Diagnostic laparotomy & $8(38.1)$ & $13(12.9)$ & \\
\hline Medical intractability & $8(40.0)$ & $12(60.0)$ & \\
\hline Perforation & $6(31.6)$ & $13(68.4)$ & \\
\hline Enterocutaneous fistula & $8(44.4)$ & $10(55.6)$ & \\
\hline Internal fistula & $3(42.9)$ & $4(57.1)$ & \\
\hline Type of primary operation & & & 0.461 \\
\hline Small bowel and colon resection & $23(27.7)$ & $60(72.3)$ & \\
\hline Small bowel resection & $19(35.8)$ & $34(64.2)$ & \\
\hline Colon resection & $5(50.0)$ & $5(50.0)$ & \\
\hline Stricturoplasty only & $0(0)$ & $1(100)$ & \\
\hline Drainage of abdominal abscess & $0(0)$ & $1(100)$ & \\
\hline Stoma formation & & & 0.327 \\
\hline Yes & $3(60.0)$ & $2(40.0)$ & \\
\hline No & $44(30.8)$ & 99 (69.2) & \\
\hline Stricturoplasty & & & 0.626 \\
\hline Yes & $8(36.4)$ & $14(63.6)$ & \\
\hline No & $39(31.0)$ & $87(69.0)$ & \\
\hline Bypass & & & 0.536 \\
\hline Yes & $1(50.0)$ & $1(50.0)$ & \\
\hline No & $46(31.5)$ & $100(68.5)$ & \\
\hline Resected bowel length (cm) & & & 0.101 \\
\hline$>40$ (median) & $16(23.2)$ & $53(76.8)$ & \\
\hline$\leq 40$ (median) & $26(36.1)$ & $46(63.9)$ & \\
\hline Postoperative complications & & & 0.272 \\
\hline Yes & $12(30.8)$ & 27 (69.2) & \\
\hline No & $27(21.5)$ & $73(78.5)$ & \\
\hline
\end{tabular}

Values are presented as number (\%). P-values were also calculated separately. CD, Crohn disease; ASA, Aminosalicylic acid; TB, tubercle bacillus.

${ }^{*} \mathrm{P}<0.05$. ${ }^{a}$ Median values. ${ }^{\mathrm{b}}$ These variables are independent of the other variables belonging to the same class. 
Table 7. Multivariate analysis of risk factors for reoperation

\begin{tabular}{lrcr}
\hline \multirow{2}{*}{ Variable } & $\begin{array}{c}\text { Univariate } \\
\text { P-value }\end{array}$ & \multicolumn{2}{c}{ Multivariate analysis } \\
\cline { 3 - 4 } & $0.050^{*}$ & OR $(95 \% \mathrm{Cl})$ & P-value \\
\hline Smoking & & & 0.605 \\
Age at diagnosis & $0.001^{*}$ & $2.20(1.12-4.31)$ & $0.023^{*}$ \\
$\quad<17$ yr (A1) & & & \\
Behavior & $<0.001^{*}$ & $4.39(2.19-8.80)$ & $<0.001^{*}$ \\
$\quad$ Penetrating (B3) & $0.009^{*}$ & $2.87(1.43-5.76)$ & $0.003^{*}$ \\
No azathioprine use & & & \\
Indication of primary operation & & - & 0.070 \\
$\quad$ Abdominal abscess or mass & $0.035^{*}$ & - & 0.077 \\
\hline Stoma formation & $<0.001^{*}$ & - &
\end{tabular}

$\mathrm{OR}$, odds ratio; $\mathrm{Cl}$, confidence interval.

${ }^{*} \mathrm{P}<0.05$.

treatment, such long-term follow-up studies of Eastern Asian patients at a single center are valuable.

The introduction of anti-TNF- $\alpha$ antibodies represented a revolutionary improvement in the treatment and management of CD. Initially, two trials, ACCENT (A Crohn's Disease Clinical Trial Evaluating Infliximab in a New Long-term Treatment Regimen in Patients With Fistulizing Crohn's Disease) I and ACCENT II, evaluated the best infliximab dosing methods in patients with $\mathrm{CD}$ $[20,21]$. More recently, adalimumab, another anti-TNF antibody, has been investigated as a second-line anti-TNF- $\alpha$ therapy for patients who have developed an intolerance to infliximab [7]. Despite some reports of infliximab-induced reductions in the recurrence rate after primary surgery $[22,23]$, no previous studies have evaluated whether anti-TNF- $\alpha$ antibody use would improve the reoperation rate among patients with $\mathrm{CD}$ who had undergone a previous operation $[24,25]$. In our study, no significant differences were observed between patients who had and had not used anti-TNF- $\alpha$ antibody therapies. Similarly, we found no significant differences between patients who underwent surgery before or after 2002, the first year during which anti-TNF- $\alpha$ antibodies were used at our institute. In Korea, anti-TNF- $\alpha$ antibodies are used to treat severe CD because of a strict insurance system that limits the use of infliximab for treating CD to patients who have already tried two other types of medications and have CDAI scores $>220$ or to those with a fistulizing CD who have already used two other kinds of treatments; accordingly, our patients who had used these drugs had more severe and more complex disease. As a result, it is difficult for Korean patients in an earlier phase of CD to obtain infliximab, a factor that might interfere with the ability to demonstrate an association between infliximab use and better treatment results. In fact, another study failed to demonstrate a reduction in the reoperation rate following the use of anti-TNF- $\alpha$ antibodies and indicated a need for earlier infliximab treatment [26]. Additional studies have suggested that top-down therapy might be more effective than conventional management for patients in re- mission [27, 28], although the effect of top-down therapy on the $\mathrm{CD}$ reoperation rate is not yet well established. Although antiTNF- $\alpha$ antibodies are currently expected to provide effective treatment for $\mathrm{CD}$, recurrent surgery still remains necessary for patients with $\mathrm{CD}$.

In our study, patients younger than 17 years at diagnosis (A1) had a higher reoperation rate. However, the influence of age on the reoperation rate among patients with $\mathrm{CD}$ remains controversial [2]. In our study, younger patients did not have a significantly longer period of disease relative to older patients (167.5 months in A1 vs. 144.8 months in others, $\mathrm{P}=0.170$ ). As a result, other disease factors might affect the reoperation rate. One study showed that patients diagnosed at a younger age tended to have a positive family history of CD and more complicated disease [29]. Another recent study reported that the phenotypes of younger patients with CD differed from those of older patients [30]. Although that study did not report a higher risk of reoperation, it suggested the existence of different intrinsic disease components in younger patients. Similarly, our study also demonstrated differences in the composition and location of CD. Approximately 59\% of A1 patients had ileocolic disease (L3) whereas approximately $62 \%$ of $\mathrm{A} 2$ and $\mathrm{A} 3$ patients had ileal disease (L1) $(\mathrm{P}=0.001)$. Finally, some studies reported an association between NOD2/ CARD15 genotypic mutations and the age at CD diagnosis [3133]; however, this mutation has not been detected in Eastern Asian patients with CD $[13,34]$.

We also observed a higher reoperation rate among patients with penetrating disease (B3). Many studies have shown an increased risk of earlier reoperation with perforating disease $[10,35,36]$, and some of these studies have suggested a trend toward recurrent perforation in patients previously treated for perforating disease. Because complicated disease behaviors such as penetrating or stricturing disease require surgical treatment [37], the reoperation rate may be higher among such patients. In the present study, more than half of the patients had penetrating disease at the primary operation, and these patients exhibited a significant likelihood of reoperation for penetrating disease $(n=23,74.2 \%, P=$ 0.038). We might consider that these disease behaviors originate from a more aggressive intrinsic disease property that leads to a higher reoperation rate among affected patients.

Only azathioprine treatment effectively prevented reoperation in this study. Azathioprine is an effective medication for the postoperative management of $\mathrm{CD}$, and some studies have reported reduced rates of surgical relapse of $\mathrm{CD}$ after long-term postsurgical thiopurine use $[38,39]$. A prospective study previously demonstrated a lower rate of clinical recurrence with azathioprine use than with mesalazine use, despite also reporting a higher azathioprine discontinuation rate because of adverse drug reactions [40]. Another study reported the preventive effect of 6-mercaptopurine, with a $27 \%$ reduction in clinical recurrence and a $16 \%$ reduction in radiological recurrence relative to a placebo group [41]. Yet another study reported reduced risks of clinical recurrence 
(relative risk $[R R], 0.59)$ and severe endoscopic recurrence (RR, 0.64 ) among patients treated with azathioprine/6-mercaptopurine [42]. Additionally, a study reported that long-term ( $>36$ months) maintenance treatment with thiopurine decreased the risk of surgical recurrence (hazard ratio, $0.41 ; \mathrm{P}=0.004$ ) [38]. In our patients, the effect of azathioprine was also superior to that of 5-aminosalicylate acid alone $(\mathrm{P}=0.033)$.

This study had some limitations. First, the study was designed retrospectively, leading to a possible failure to evaluate many factors associated with the CD status because of missing data. Selection bias resulting from the operator's inclination is also possible. The small study size relative to those in Western studies also hindered the evaluation of other variables that had been identified as potential risk factors. Nevertheless, our study is unique among Asian populations, in which the incidence of $\mathrm{CD}$ is increasing, as we have included long-term ( $>35$ years) surgical outcomes and an analysis of anti-TNF- $\alpha$ antibody use.

In summary, our long-term follow-up results confirmed a high rate of reoperation for gastrointestinal $\mathrm{CD}$ in the Korean population. An age $<17$ years at diagnosis, penetrating disease behavior, and no azathioprine use were verified risk factors for reoperation. However, we were unable to demonstrate a prophylactic effect of anti-TNF- $\alpha$ antibody therapy against reoperation.

\section{CONFLICT OF INTEREST}

No potential conflict of interest relevant to this article was reported.

\section{REFERENCES}

1. Crohn BB, Ginzburg L, Oppenheimer GD. Regional ileitis: a pathologic and clinical entity. JAMA 1932;99:1323-9.

2. Yamamoto T. Factors affecting recurrence after surgery for Crohn's disease. World J Gastroenterol 2005;11:3971-9.

3. Shivananda S, Hordijk ML, Pena AS, Mayberry JF. Crohn's disease: risk of recurrence and reoperation in a defined population. Gut 1989;30:990-5.

4. Munkholm P, Langholz E, Davidsen M, Binder V. Disease activity courses in a regional cohort of Crohn's disease patients. Scand J Gastroenterol 1995;30:699-706.

5. Bernell O, Lapidus A, Hellers G. Risk factors for surgery and postoperative recurrence in Crohn's disease. Ann Surg 2000;231:38-45.

6. Regueiro M, Schraut W, Baidoo L, Kip KE, Sepulveda AR, Pesci M, et al. Infliximab prevents Crohn's disease recurrence after ileal resection. Gastroenterology 2009;136:441-50.e1.

7. Sandborn WJ, Hanauer SB, Rutgeerts P, Fedorak RN, Lukas M, MacIntosh DG, et al. Adalimumab for maintenance treatment of Crohn's disease: results of the CLASSIC II trial. Gut 2007;56: 1232-9.

8. De Cruz P, Kamm MA, Hamilton AL, Ritchie KJ, Krejany EO, Gorelik A, et al. Crohn's disease management after intestinal re- section: a randomised trial. Lancet 2015;385:1406-17.

9. Borley NR, Mortensen NJ, Jewell DP. Preventing postoperative recurrence of Crohn's disease. Br J Surg 1997;84:1493-502.

10. Unkart JT, Anderson L, Li E, Miller C, Yan Y, Gu CC, et al. Risk factors for surgical recurrence after ileocolic resection of Crohn's disease. Dis Colon Rectum 2008;51:1211-6.

11. Simillis C, Yamamoto T, Reese GE, Umegae S, Matsumoto K, Darzi AW, et al. A meta-analysis comparing incidence of recurrence and indication for reoperation after surgery for perforating versus nonperforating Crohn's disease. Am J Gastroenterol 2008; 103:196-205.

12. Lindberg E, Jarnerot G, Huitfeldt B. Smoking in Crohn's disease: effect on localisation and clinical course. Gut 1992;33:779-82.

13. Inoue N, Tamura K, Kinouchi Y, Fukuda Y, Takahashi S, Ogura Y, et al. Lack of common NOD2 variants in Japanese patients with Crohn's disease. Gastroenterology 2002;123:86-91.

14. Ng SC, Tsoi KK, Kamm MA, Xia B, Wu J, Chan FK, et al. Genetics of inflammatory bowel disease in Asia: systematic review and meta-analysis. Inflamm Bowel Dis 2012;18:1164-76.

15. Satsangi J, Silverberg MS, Vermeire S, Colombel JF. The Montreal classification of inflammatory bowel disease: controversies, consensus, and implications. Gut 2006;55:749-53.

16. Eveleth PB. Physical status: the use and interpretation of anthropometry. Report of a WHO Expert Committee. Am J Hum Biol 1996;8:786-7.

17. Yang SK, Yun S, Kim JH, Park JY, Kim HY, Kim YH, et al. Epidemiology of inflammatory bowel disease in the Songpa-Kangdong district, Seoul, Korea, 1986-2005: a KASID study. Inflamm Bowel Dis 2008; 14:542-9.

18. Ahuja V, Tandon RK. Inflammatory bowel disease in the AsiaPacific area: a comparison with developed countries and regional differences. J Dig Dis 2010;11:134-47.

19. Nordgren SR, Fasth SB, Oresland TO, Hulten LA. Long-term follow-up in Crohn's disease. Mortality, morbidity, and functional status. Scand J Gastroenterol 1994;29:1122-8.

20. Hanauer SB, Feagan BG, Lichtenstein GR, Mayer LF, Schreiber S, Colombel JF, et al. Maintenance infliximab for Crohn's disease: the ACCENT I randomised trial. Lancet 2002;359:1541-9.

21. Sands BE, Anderson FH, Bernstein CN, Chey WY, Feagan BG, Fedorak RN, et al. Infliximab maintenance therapy for fistulizing Crohn's disease. N Engl J Med 2004;350:876-85.

22. Araki T, Uchida K, Okita Y, Fujikawa H, Inoue M, Ohi M, et al. Impact of postoperative infliximab maintenance therapy on preventing the surgical recurrence of Crohn's disease: a single-center paired case-control study. Surg Today 2014;44:291-6.

23. Sorrentino D, Paviotti A, Terrosu G, Avellini C, Geraci M, Zarifi D. Low-dose maintenance therapy with infliximab prevents postsurgical recurrence of Crohn's disease. Clin Gastroenterol Hepatol 2010;8:591-9.e1.

24. Jones DW, Finlayson SR. Trends in surgery for Crohn's disease in the era of infliximab. Ann Surg 2010;252:307-12.

25. Lazarev M, Ullman T, Schraut WH, Kip KE, Saul M, Regueiro M. 
Small bowel resection rates in Crohn's disease and the indication for surgery over time: experience from a large tertiary care center. Inflamm Bowel Dis 2010;16:830-5.

26. Fu YT, Hong T, Round A, Bressler B. Impact of medical therapy on patients with Crohn's disease requiring surgical resection. World J Gastroenterol 2014;20:11808-14.

27. Armuzzi A, De Pascalis B, Fedeli P, De Vincentis F, Gasbarrini A. Infliximab in Crohn's disease: early and long-term treatment. Dig Liver Dis 2008;40 Suppl 2:S271-9.

28. Khanna R, Levesque BG, Bressler B, Zou G, Stitt L, Greenberg $\mathrm{GR}$, et al. Early combined immunosuppression for the management of Crohn's disease: a community-based cluster randomized trial [abstract]. Gastroenterology 2014;146(5 Suppl 1):S187. Abstract No. 1053.

29. Polito JM 2nd, Childs B, Mellits ED, Tokayer AZ, Harris ML, Bayless TM. Crohn's disease: influence of age at diagnosis on site and clinical type of disease. Gastroenterology 1996;111:580-6.

30. Israeli E, Ryan JD, Shafer LA, Bernstein CN. Younger age at diagnosis is associated with panenteric, but not more aggressive, Crohn's disease. Clin Gastroenterol Hepatol 2014;12:72-9.e1.

31. Lakatos PL, Lakatos L, Szalay F, Willheim-Polli C, Osterreicher C, Tulassay Z, et al. Toll-like receptor 4 and NOD2/CARD15 mutations in Hungarian patients with Crohn's disease: phenotype-genotype correlations. World J Gastroenterol 2005;11:1489-95.

32. Lesage S, Zouali H, Cezard JP, Colombel JF, Belaiche J, Almer S, et al. CARD15/NOD2 mutational analysis and genotype-phenotype correlation in 612 patients with inflammatory bowel disease. Am J Hum Genet 2002;70:845-57.

33. Helio T, Halme L, Lappalainen M, Fodstad H, Paavola-Sakki P, Turunen U, et al. CARD15/NOD2 gene variants are associated with familially occurring and complicated forms of Crohn's disease. Gut 2003;52:558-62.

34. Leong RW, Armuzzi A, Ahmad T, Wong ML, Tse P, Jewell DP, et al. NOD2/CARD15 gene polymorphisms and Crohn's disease in the
Chinese population. Aliment Pharmacol Ther 2003;17:1465-70.

35. Greenstein AJ, Lachman P, Sachar DB, Springhorn J, Heimann T, Janowitz HD, et al. Perforating and non-perforating indications for repeated operations in Crohn's disease: evidence for two clinical forms. Gut 1988;29:588-92.

36. Sachar DB, Lemmer E, Ibrahim C, Edden Y, Ullman T, Ciardulo J, et al. Recurrence patterns after first resection for stricturing or penetrating Crohn's disease. Inflamm Bowel Dis 2009;15:1071-5.

37. Ryan JD, Silverberg MS, Xu W, Graff LA, Targownik LE, Walker JR, et al. Predicting complicated Crohn's disease and surgery: phenotypes, genetics, serology and psychological characteristics of a population-based cohort. Aliment Pharmacol Ther 2013;38:27483.

38. Papay P, Reinisch W, Ho E, Gratzer C, Lissner D, Herkner H, et al. The impact of thiopurines on the risk of surgical recurrence in patients with Crohn's disease after first intestinal surgery. Am J Gastroenterol 2010;105:1158-64.

39. Cuillerier E, Lemann M, Bouhnik Y, Allez M, Rambaud JC, Modigliani R. Azathioprine for prevention of postoperative recurrence in Crohn's disease: a retrospective study. Eur J Gastroenterol Hepatol 2001;13:1291-6.

40. Reinisch W, Angelberger S, Petritsch W, Shonova O, Lukas M, Bar-Meir S, et al. Azathioprine versus mesalazine for prevention of postoperative clinical recurrence in patients with Crohn's disease with endoscopic recurrence: efficacy and safety results of a randomised, double-blind, double-dummy, multicentre trial. Gut 2010;59:752-9.

41. Hanauer SB, Korelitz BI, Rutgeerts P, Peppercorn MA, Thisted $\mathrm{RA}$, Cohen RD, et al. Postoperative maintenance of Crohn's disease remission with 6-mercaptopurine, mesalamine, or placebo: a 2-year trial. Gastroenterology 2004;127:723-9.

42. Doherty G, Bennett G, Patil S, Cheifetz A, Moss AC. Interventions for prevention of post-operative recurrence of Crohn's disease. Cochrane Database Syst Rev 2009;(4):CD006873. 